\title{
Oral Drugs for Unexplained Infertility
}

\author{
Gautam N. Allahbadia ${ }^{1}$
}

Published online: 13 November 2015

(C) Federation of Obstetric \& Gynecological Societies of India 2015

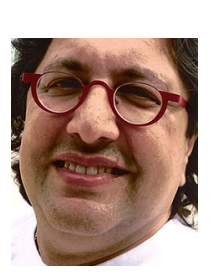

\begin{abstract}
About the Author
Gautam N. Allahbadia, MD is the Editor-in-Chief of the Journal of Obstetrics \& Gynecology of India as well as the IVF Lite (Journal of Minimal Stimulation IVF). He is the Medical Director of Rotunda-The Center for Human Reproduction, the world-renowned infertility clinic at Bandra, and Rotunda-Blue Fertility Clinic and Keyhole Surgery Center, Mumbai, India. $\mathrm{He}$ is a noted world authority on ultrasound-guided embryo transfers and one of the pioneers in Third Party Reproduction in Southeast Asia. Dr. Allahbadia was responsible for India's first trans-ethnic surrogate pregnancy involving a Chinese couple's baby delivered by an unrelated Indian surrogate mother. He cherishes over 125 peer-reviewed publications, 134 book chapters and 22 textbooks, the latest being a comprehensive text, entitled "Minimal Stimulation IVF", and is on the Editorial Board of several International Journals. He just completed a two year tenure as Medical Director at the New Hope IVF Clinic, Sharjah, UAE where he introduced IVF Lite to the country. Dr. Allahbadia has recently been elected as the Vice President of the World Association of Reproductive Medicine (WARM), headquartered in Rome, and "Mumbai's Top Doc" for 2012 by a peer nomination
\end{abstract} process. You can read more about his work at www.gautamallahbadia.com.

\begin{abstract}
Of the infertile couples unable to conceive without any identifiable cause, $30 \%$ are defined as having unexplained infertility. Management depends on duration of infertility and age of female partner. The treatment of unexplained infertility is empirical, and many different regimens have been used. Among these are expectant management, ovarian stimulation with clomiphene citrate,
\end{abstract}

Gautam N. Allahbadia, MD is the Editor-in-Chief of the Journal of Obstetrics \& Gynecology of India as well as the IVF Lite (Journal of Minimal Stimulation IVF) and Medical Director of Rotunda-The Center for Human Reproduction, Bandra, and Rotunda-Blue Fertility Clinic and Keyhole Surgery Center, Parel, Mumbai, India.

Gautam N. Allahbadia

ivfwaladoc@gmail.com

1 Rotunda-The Center For Human Reproduction, Mumbai, India gonadotropins and aromatase inhibitors, fallopian tube sperm perfusion, tubal flushing, intrauterine insemination, gamete intrafallopian transfer, and IVF. The first approach to treatment of unexplained infertility generally is the use of drugs that stimulate oocyte production. For over four decades, the first-line treatment for ovarian stimulation in unexplained infertility has been clomiphene citrate. Multiple reports suggest that aromatase inhibitors may be effective alternative agents for ovarian stimulation in couples with unexplained infertility. Their administration is reported to be associated with monofollicular development in most cases, which may result in enhanced fertility and a reduced risk of ovarian hyperstimulation and multiple births, as compared to current standard therapies such as gonadotropin and clomiphene. Despite world evidence to the contrary, letrozole has been banned for use for infertility management in India since 2011. 
Keywords Oral drugs - Unexplained infertility . Clomiphene citrate - Letrozole - Infertile couples . Aromatase inhibitors · IUI

\section{Introduction}

Infertility occurs in about $15 \%$ of couples. About one-third of cases are due to problems with ovulation or other female factors, another third are due to a male infertility factor, and the remaining third are unexplained. In older women, unexplained infertility is probably caused by diminished quality and quantity of oocytes. The first approach to treatment of female factor infertility generally is the use of drugs that stimulate oocyte production. Empirical ovarian stimulation has been thought to promote childbearing by increasing the number of ova ovulated, as well as possibly by enhancing implantation, placentation, or both through hormonal effects on the endometrium [1-3]. However, empirical ovarian stimulation (with clomiphene or particularly with gonadotropin) is frequently complicated by the ovarian hyperstimulation syndrome and by multiple gestations, with an increased risk of preterm birth and associated neonatal morbidity and costs [4-9]. Recent studies have found that aromatase inhibitors including letrozole may be safe and useful agents for ovulation induction in patients with unexplained infertility [10-12]. Letrozole has been used for ovarian stimulation by fertility doctors since 2001 because it has fewer side effects than clomiphene citrate and less chance of multiple gestations [10-12]. A detailed ovulation induction follow-up study found that letrozole, compared with a control group of clomiphene, had significantly lower congenital malformations and chromosomal abnormalities at an overall rate of $2.4 \%$ (1.2\% major malformations) compared with clomiphene $4.8 \%$ (3.0\% major malformations) [13]. Despite this, India banned the usage of letrozole in 2011, citing potential risks to infants [14]. In 2012, an Indian parliamentary committee said that the drug controller office colluded with letrozole's makers to approve the drug for infertility in India and also stated that letrozole's use for infertility was illegal worldwide [15]; however, such off-label uses are legal in many countries such as the US and UK $[16,17]$.

\section{Discussion}

For over four decades, the first-line treatment for ovarian stimulation in unexplained infertility has been clomiphene citrate. Clomiphene is an effective and safely used oral drug, but is known to have relatively common anti-estrogenic endometrial and cervical mucus adverse effects that could decrease chances of pregnancy. In addition, there is a significant risk of multiple pregnancies with clomiphene citrate compared with natural cycles. These drawbacks are mainly a result of the extended anti-estrogenic effect of clomiphene as a result of its accumulation in the body (clomiphene isomers have a half-life of several days up to few weeks) [18]. Because of these problems, Mitwally and Casper proposed the concept of using aromatase inhibitors as a new method of ovulation induction that could avoid many of the adverse effects of clomiphene [18]. Over the last few years, several published studies, both controlled and non-controlled, compared clomiphene and treatment with aromatase inhibitors (AIs), either alone or in combination with gonadotropins, for ovarian stimulation for indications including unexplained infertility $[19,20]$. These studies found AIs as effective as clomiphene in inducing ovulation, with the major advantage of absence of any anti-estrogenic adverse effects. Several other major advantages of AIs include the lower serum estrogen production per developing follicle resulting in more physiological estrogen levels around the time of ovulation and good pregnancy rates with a lower incidence of multiple pregnancy than with clomiphene [18]. Such preliminary evidence suggested that AIs may replace clomiphene in the future because of similar efficacy with a reduced adverse effect profile. But other prospective studies concluded that letrozole and clomiphene have comparable effectiveness in ovulatory patients with unexplained infertility [21].

Diamond et al. [22] enrolled couples with unexplained infertility in a multicenter, randomized trial. Ovulatory women 18-40 years of age with at least one patent fallopian tube were randomly assigned to ovarian stimulation (up to four cycles) with gonadotropin (301 women), clomiphene (300), or letrozole (299). The primary outcome was the rate of multiple gestations among women with clinical pregnancies. After treatment with gonadotropin, clomiphene, or letrozole, clinical pregnancies occurred in $35.5,28.3$, and $22.4 \%$ of cycles and live birth in 32.2, 23.3 , and $18.7 \%$, respectively; pregnancy rates with letrozole were significantly lower than the rates with standard therapy (gonadotropin or clomiphene) $(P=0.003)$ or gonadotropin alone $(P<0.001)$, but not with clomiphene alone $(P=0.10)$. Among ongoing pregnancies with fetal heart activity, the multiple gestation rate with letrozole (9 of 67 pregnancies, $13 \%$ ) did not differ significantly from the rate with gonadotropin or clomiphene (42 of $192,22 \% ; P=0.15)$ or clomiphene alone (8 of $85,9 \% ; P=0.44$ ) but was lower than the rate with gonadotropin alone (34 of 107, $32 \% ; P=0.006$ ). All multiple gestations in the clomiphene and letrozole groups were twins, whereas gonadotropin treatment resulted in 24 twin and 10 triplet gestations. There were no significant differences among groups in the frequencies of congenital anomalies or major fetal and neonatal complications. In 
women with unexplained infertility, ovarian stimulation with letrozole resulted in a significantly lower frequency of multiple gestations but also a lower frequency of live birth, as compared to gonadotropin, but not as compared to clomiphene [22].

Badawy et al. [23] evaluated the pregnancy outcome after ovulation induction with aromatase inhibitors or clomiphene citrate (CC). The prospective study comprised a total of 796 infertile women (1100 cycles) and 200 spontaneously pregnant women (298 cycles) as a control group. Patients were allocated treatment with either $100 \mathrm{mg}$ of CC daily (420 patients, 634 cycles), $5 \mathrm{mg}$ of letrozole daily (269 patients, 323 cycles), or $1 \mathrm{mg}$ of anastrozole daily (107 patients, 143 cycles) for 5 days starting on day 3 of menses. Pregnancy occurred in 167/1398 cycles (11.9\%) in total without significant differences between groups. The total miscarriage rate was $16.1 \%$ (varied between $14.2 \%$ in CC group and $19.9 \%$ in anastrozole group) without difference between spontaneous and stimulated pregnancies. There were 129 deliveries in all groups. There were no significant differences between the stimulated and spontaneous pregnancies as regards mean gestational age, premature deliveries, birth weight, $\mathrm{SGA}<10$ th percentile, or 5-min Apgar score. There were one case of complete cleft palate and one case of major congenital heart problem in the letrozole group. There were two cases of talipes equinovarus in the $\mathrm{CC}$ and spontaneous pregnancy group. The authors concluded that aromatase inhibitors and CC resulted in favorable pregnancy outcomes and average miscarriage rates. Safety of the drugs for both the mother and fetuses was documented [23].

In a prospective randomized trial setup by Shokeir [24], 66 consecutive women with unexplained infertility were recruited for the study. Thirty-six women received tamoxifen citrate (TMX) at a 20-mg dosage, and 30 women received no ovulation induction drugs. Fourteen patients in the TMX group stopped taking TMX, and observations were terminated because of anti-estrogenic effects. The pregnancy rate (PR) per patient and the PR per cycle were significantly decreased $(P<0.005)$ in the TMX group than in the spontaneous group. Kaplan-Meier tests showed that the cumulative PR in the TMX group was significantly lower than in the spontaneous group $(P<0.05)$. Ten of 14 patients who had stopped taking TMX became pregnant in spontaneous cycles. Administration of tamoxifen to women with unexplained infertility is not efficacious in terms of increasing the clinical PR [24].

Shahin et al.'s study [25] investigated the role of oral phytoestrogens in improving pregnancy rate and cycle outcomes with clomiphene citrate. Patients with unexplained infertility and recurrent clomiphene citrate induction failure were randomly divided into two groups: group I $(n=60)$ and group II $(n=59)$. Both groups received clomiphene citrate $150 \mathrm{mg}$ per day (days 3-7). Group I received additional oral phytoestrogen (Cimicifuga racemosa) $120 \mathrm{mg} /$ day from days $1-12$. Human chorionic gonadotropin (HCG) injection (10,000 IU i.m.) was given, and timed intercourse was recommended when a leading follicle reached $>17 \mathrm{~mm}$ and serum estradiol exceeded 200 $(\mathrm{pg} / \mathrm{ml})$. There was a nonsignificant shortening of induction cycles in group I. Estradiol and LH concentrations were higher in group I compared with group II. Endometrial thickness, serum progesterone, and clinical pregnancy rate were significantly higher in group I $(8.9 \pm 1.4 \mathrm{~mm}$ versus $7.5 \pm 1.3 \mathrm{~mm}, \quad P<0.001 ; \quad 13.3 \pm 3.1 \mathrm{ng} / \mathrm{ml} \quad$ versus $9.3 \pm 2.0 \mathrm{ng} / \mathrm{ml}, \quad P<0.01 ; \quad 36.7 \%$ versus $13.6 \%$, $P<0.01$, respectively). The study concluded that adding C. racemosa rhizome dry extract to clomiphene citrate induction can improve the pregnancy rate and cycle outcomes in these couples [25].

Leanza et al. evaluated the success rate after homologous intrauterine insemination (IUI) combined with clomiphene citrate (CC) stimulation in 77 couples with unexplained infertility [26]. Nine couples (11.6\%) were excluded from the treatment (vaginal infections 4 , tubal occlusions 3 , and male sterility 2 ). Informed consent was applied for every couple. The remaining 68 couples were divided into two groups: group A (34 couples) were inducted with CC, while group B (34 couples) underwent placebo (multivitamin). In group A (CC), 15 (44.1\%) pregnancies and three $(8.8 \%)$ abortions were registered, while in group B (placebo) there were four $(11.7 \%)$ pregnancies and one $(2.9 \%)$ abortion. The authors concluded that stimulation with $\mathrm{CC}$, together with intrauterine insemination, improves fecundity in patients with infertility of unknown origin with no need to recur to more invasive techniques [26]. The same group next evaluated the success rate after homologous intrauterine insemination (IUI) combined with menopausal gonadotropin stimulation [27]. Seventy-eight couples were divided into two groups: group A (39 couples) were inducted with menopausal gonadotropins, while group B (39 couples) underwent placebo (multivitamin). In group A (gonadotropins), 25 (64.1\%) pregnancies and two $(5.1 \%)$ abortions were registered, while in group B (placebo) there were seven $(17.9 \%)$ pregnancies and one $(2.5 \%)$ abortion [27].

Goldman et al. [28] set up an elegant randomized clinical trial to determine the optimal infertility therapy for women with unexplained infertility at the end of their reproductive potential. Couples with $\geq 6$ months of unexplained infertility with female partner aged 38-42 years were included. They randomized 154 couples to receive CC/IUI $(N=51)$, FSH/IUI $(N=52)$, or immediate IVF $(N=51) ; 140(90.9 \%)$ couples initiated treatment. The cumulative clinical pregnancy rates per couple after the first two cycles of CC/IUI, FSH/IUI, or immediate IVF were $21.6,17.3$, and $49.0 \%$, respectively. After all 
treatments, $110(71.4 \%)$ of 154 couples had conceived a clinically recognized pregnancy, and $46.1 \%$ had delivered at least one live-born baby; $84.2 \%$ of all live-born infants resulting from treatment were achieved via IVF. There were $36 \%$ fewer treatment cycles in the IVF arm compared with either $\mathrm{COH} / \mathrm{IUI}$ arm, and the couples conceived a pregnancy leading to a live birth after fewer treatment cycles. This paper suggested that a randomized controlled trial in older women with unexplained infertility to compare treatment initiated with two cycles of controlled ovarian hyperstimulation/IUI versus immediate IVF demonstrated superior pregnancy rates with fewer treatment cycles in the immediate IVF group [28].

\section{Recent Advances}

Yapca et al. [29] evaluated time-limited hydrotubation combined with clomiphene citrate as treatment for unexplained infertility. In this unblinded, randomized controlled trial of patients who had unexplained infertility, 40 patients were treated with time-limited hydrotubation (saline, $20 \mathrm{ml}$; flushed within 20-30 s) and clomiphene citrate (total, 70 cycles), and 40 patients were treated with clomiphene citrate alone (total, 74 cycles). All women underwent an ovulation induction protocol with clomiphene citrate $(100 \mathrm{mg} / \mathrm{d}$ orally for 5 days, from day 3 to day 7 of the cycle). Hydrotubation was performed after detection of the dominant follicle. There were 15 pregnancies in the 80 patients (19\%) (total, 144 stimulated cycles; $10 \%$ pregnancies per cycle). The frequency of clinical pregnancy per cycle was significantly greater in patients who were treated with hydrotubation and clomiphene citrate (nine pregnancies per cycle [13\%]) than those treated with clomiphene citrate alone (two pregnancies per cycle [3\%]; odds ratio 5.3; $95 \%$ confidence interval $1.1-25.5 ; P \leq 0.05)$. The frequency of pregnancy per patient (total, clinical, or chemical) was similar for the two treatment groups. The frequency of live birth or abortion per cycle or patient was similar between the two treatment groups. The paper concludes that time-limited hydrotubation and clomiphene citrate may increase the frequency of clinical pregnancy per cycle in women who have unexplained infertility [29]. Is this not strange that history is repeating itself after half a century even in basic fertility management techniques?

\section{Conclusions}

For patients diagnosed with unexplained infertility, recent information has allowed the diagnosis to be viewed with hope. With a better understanding of the efficacy and use of empiric therapies, unexplained infertility has gone from a diagnosis filled with uncertainty and despair to one that when treated appropriately has a positive outlook. Appropriate initial treatment for unexplained infertility can be managed in the office by their primary gynecologists with the administration of available and approved oral ovulation induction medications combined with intrauterine insemination. For older women with unexplained infertility, an immediate IVF will give the best results.

\section{References}

1. Ghesquiere SL, Castelain EG, Spiessens C, et al. Relationship between follicle number and (multiple) live birth rate after controlled ovarian hyperstimulation and intrauterine insemination. Am J Obstet Gynecol. 2007;197:589.e1-5.

2. Samani FG, Farzadi L, Nezami N, et al. Endometrial and follicular development following letrozole intervention in unexplained infertile patients failed to get pregnant with clomiphene citrate. Arch Gynecol Obstet. 2009;280:201-5.

3. Fisch P, Casper RF, Brown SE, et al. Unexplained infertility: evaluation of treatment with clomiphene citrate and human chorionic gonadotropin. Fertil Steril. 1989;51:828-33.

4. Practice Committee of American Society for Reproductive Medicine. Multiple gestation associated with infertility therapy: an American Society for Reproductive Medicine Practice Committee opinion. Fertil Steril. 2012;97:825-34.

5. Reynolds MA, Schieve LA, Martin JA, et al. Trends in multiple births conceived using assisted reproductive technology, United States, 1997-2000. Pediatrics. 2003;111:1159-62.

6. Schieve LA, Devine O, Boyle CA, et al. Estimation of the contribution of non-assisted reproductive technology ovulation stimulation fertility treatments to US singleton and multiple births. Am J Epidemiol. 2009; 170:1396-407.

7. Cook JL, Geran L, Rotermann M. Multiple births associated with assisted human reproduction in Canada. J Obstet Gynaecol Can. 2011;33:609-16.

8. Guzick DS, Carson SA, Coutifaris C, et al. Efficacy of superovulation and intrauterine insemination in the treatment of infertility. N Engl J Med. 1999;340:177-83.

9. Kulkarni AD, Jamieson DJ, Jones HW Jr, et al. Fertility treatments and multiple births in the United States. N Engl J Med. 2013;369:2218-25.

10. Ibrahim MI, Moustafa RA, Abdel-Azeem AA. Letrozole versus clomiphene citrate for superovulation in Egyptian women with unexplained infertility: a randomized controlled trial. Arch Gynecol Obstet. 2012;286(6):1581-7. doi:10.1007/s00404012-2478-0.

11. Liu A, Zheng C, Lang J, et al. Letrozole versus clomiphene citrate for unexplained infertility: a systematic review and meta-analysis. J Obstet Gynaecol Res. 2014;40(5):1205-16. doi:10.1111/jog.12393.

12. Pavone ME, Bulun SE. Clinical review: the use of aromatase inhibitors for ovulation induction and superovulation. J Clin Endocrinol Metab. 2013;98(5):1838-44. doi:10.1210/jc.20131328.

13. Tulandi T, Martin J, Al-Fadhli R. Congenital malformations among 911 newborns conceived after infertility treatment with letrozole or clomiphene citrate. Fertil Steril. 2006;85(6):1761-5. doi:10.1016/j.fertnstert.2006.03.014.

14. Sinha K (18 October 2011). "Finally, expert panel bans fertility drug Letrozole". The Times of India. http://timesofindia. indiatimes.com/india/Finally-expert-panel-bans-fertility-drugLetrozole/articleshow/10395119.cms Retrieved 27 Sep 2015. 
15. "House panel to govt: Punish those guilty of approving Letrozole". The Times of India. 9 May 2012. http://timesofindia. indiatimes.com/india/House-panel-to-govt-Punish-those-guiltyof-approving-Letrozole/articleshow/13059757.cms?referral=PM Retrieved 27 September 2015.

16. Chen DT, Wynia MK, Moloney RM, et al. Physician knowledge of the FDA-approved indications of commonly prescribed drugs: results of a national survey. Pharmacoepidemiol Drug Saf. 2009;18(11):1-7. doi:10.1002/pds.1825.

17. "GMCl Good practice in prescribing medicines-guidance for doctors". GMC-UK.org. 16 February 2007. http://www.gmc-uk. org/Good_Practice_in_Prescribing_Medicines.pdf_25416575.pdf Retrieved 27 Sep 2015.

18. Mitwally MF, Casper RF. Potential of aromatase inhibitors for ovulation and superovulation induction in infertile women. Drugs. 2006;66(17):2149-60.

19. Sakhavar N, Kaveh M, Sadegi K. The impact of letrozole versus clomiphene citrate on uterine blood flow in patients with unexplained infertility. J Family Reprod Health. 2014;8(1):1-5.

20. Chaudhury K, Chaudhury S, Khastgir G, et al. An effective alternative to only gonadotrophin for controlled ovarian stimulation in unexplained infertility patients undergoing intra-uterine insemination: a clinical trial. J Indian Med Assoc. 2013;111(9): 589-92, 594.

21. Bayar U, Tanriverdi HA, Barut A, et al. Letrozole vs. clomiphene citrate in patients with ovulatory infertility. Fertil Steril. 2006; 85(4):1045-8.

22. Diamond MP, Legro RS, Coutifaris C, et al. NICHD reproductive medicine network. Letrozole, gonadotropin, or clomiphene for unexplained infertility. N Engl J Med. 2015;373(13):1230-40. doi:10.1056/NEJMoa1414827.

23. Badawy A, Shokeir T, Allam AF, et al. Pregnancy outcome after ovulation induction with aromatase inhibitors or clomiphene citrate in unexplained infertility. Acta Obstet Gynecol Scand. 2009;88(2):187-91. doi:10.1080/00016340802638199.

24. Shokeir TA. Tamoxifen citrate for women with unexplained infertility. Arch Gynecol Obstet. 2006;274(5):279-83.

25. Shahin AY, Ismail AM, Zahran KM, et al. Adding phytoestrogens to clomiphene induction in unexplained infertility patientsa randomized trial. Reprod Biomed. 2008;16(4):580-8.

26. Leanza V, Coco L, Grasso F, et al. Ovulation induction with clomiphene citrate for infertile couple. Minerva Ginecol. 2014;66(3):309-12.

27. Leanza V, Coco L, Grasso F, et al. Unexplained infertility and ovulatory induction with menopausal gonadotropins. Minerva Ginecol. 2014;66(3):303-7.

28. Goldman MB, Thornton KL, Ryley D, et al. A randomized clinical trial to determine optimal infertility treatment in older couples: the Forty and Over Treatment Trial (FORT-T). Fertil Steril. 2014;101(6):1574-81.e1-2. doi:10.1016/j.fertnstert.2014. 03.012.

29. Yapca OE, Delibas IB, Karaca I, et al. Time-limited hydrotubation combined with clomiphene citrate treatment for unexplained infertility. Clin Exp Obstet Gynecol. 2015;42(3):311-4. 